\title{
Laboreal
}

Volume $15 \mathrm{~N}^{\circ} 1$ | 2019

Trabalho e cooperação

\section{A conceção em design industrial e em arquitetura: desejo, pertinência, cooperação e cognição}

Texto original: Lebahar, J.-Ch. (2007). La conception en design industriel et en architecture. Désir, pertinence, coopération et cognition (pp. 15-21). Paris: Hermes-Lavoisier.

Concepción en diseño industrial y arquitectura : deseo, pertinencia, cooperación y cognición

La conception en design industriel et en architecture: désir, pertinence, coopération et cognition

The conception in industrial design and architecture: desire, pertinence, cooperation and cognition

\section{Jean-Charles Lebahar}

Tradutor. João Viana Jorge

\section{(2) OpenEdition}

\section{Journals}

\section{Edição electrónica}

URL: http://journals.openedition.org/laboreal/1645

DOI: 10.4000/laboreal. 1645

ISSN: 1646-5237

\section{Editora}

Universidade do Porto

Refêrencia eletrónica

Jean-Charles Lebahar, «A conceção em design industrial e em arquitetura: desejo, pertinência, cooperação e cognição », Laboreal [Online], Volume $15 N^{0} 1$ | 2019, posto online no dia 01 dezembro 2018, consultado o 24 setembro 2020. URL : http://journals.openedition.org/laboreal/1645; DOI : https://doi.org/10.4000/laboreal.1645

Este documento foi criado de forma automática no dia 24 setembro 2020. 


\section{A conceção em design industrial e em arquitetura: desejo, pertinência, cooperação e cognição}

Texto original: Lebahar, J.-Ch. (2007). La conception en design industriel et en architecture. Désir, pertinence, coopération et cognition (pp. 15-21). Paris: Hermes-Lavoisier.

Concepción en diseño industrial y arquitectura : deseo, pertinencia, cooperación y cognición

La conception en design industriel et en architecture: désir, pertinence, coopération et cognition

The conception in industrial design and architecture: desire, pertinence, cooperation and cognition

Jean-Charles Lebahar

Tradução : João Viana Jorge

\section{REFERÊNCIA}

Texto original: Lebahar, J.-Ch. (2007). La conception en design industriel et en architecture. Désir, pertinence, coopération et cognition (pp. 15-21). Paris: HermesLavoisier.

\section{Introdução}

1 O homem concebe e utiliza artefactos, quer dizer objetos artificiais a começar pelas palavras que emprega para designar as coisas ou comunicar os seus pensamentos até ao computador portátil, passando pelo pente, a pintura que tinge e protege as paredes da casa, a própria casa ou a lei que se brande perante a injustiça. Para H. A. Simon este 
facto é uma evidência: «O mundo em que vivemos hoje é mais um mundo artificial feito pelo homem do que um mundo natural. Quase todos os elementos da nossa envolvente mostram a evidência do artifício humano» (Simon, 1991, p. 2).

Pode definir-se a atividade de conceção como a construção e a comunicação de um modelo de artefacto não resultante da réplica de um modelo (já) existente. Esta construção 'cognitiva' baseia-se em conhecimentos e na utilização que deles fazem os profissionais (arquitetos, designers, desenhadores, engenheiros, etc.) para produzir as informações que definem os atributos do novo artefacto (as formas de uma carroceria de automóvel, as funções de um computador portátil, a estética de uma construção, a ergonomia de um comando rádio, etc.). Para simular, avaliar e comunicar essas informações, aqueles sujeitos estabelecem representações que exprimem sob a forma de modelos: desenhos, objetos geométricos, maquetas, imagens numéricas, sistemas de símbolos, etc..

3 A análise da atividade reunidas neste livro, sob a forma de estudos de caso estão centradas num sujeito psicológico que concebe artefactos, um 'sujeito concetor' (SC) no domínio da arquitetura e do design industrial, quer se trate de uma situação operacional quer didática.

Geralmente uma tarefa de conceção é prescrita sob a forma de encomenda de um artefacto. Constitui um estado inicial de representação do artefacto a conceber e pode ser comunicada a um SC sob diversas formas (um caderno de encargos redigido de acordo com as normas industriais; uma discussão por etapas entre um arquiteto e o seu cliente, um professor atribuindo um exercício de elaboração de um projeto a um estudante, uma sessão de criatividade reunindo um ou diversos designers convocados por um agente comercial e/ou industrial com o fim de elaborar o conceito de um novo produto, etc.). $\mathrm{O}$ estado inicial de representação do artefacto contido numa encomenda fornece ao SC informações mais ou menos completas, mais ou menos precisas, mais ou menos fiáveis e mais ou menos corretas sobre esse artefacto.

5 Noutros termos, o SC não pode considerar única e imediatamente estas informações como satisfatórias para compreender o problema que lhe coloca a elaboração e a comunicação da representação definitiva do artefacto: o modelo que permitirá a sua realização material (planos de execução, uma maqueta sólida ou numérica, etc.).

6 Este modelo tem por função guiar as ações daqueles que serão encarregados dessa realização num estaleiro ${ }^{1}$ ou numa fábrica, com a ajuda de máquinas ou de qualquer espécie de utensílios. Um modelo deste tipo deve definir, com a menor ambiguidade possível, um artefacto que esteja de acordo com um certo número de constrangimentos. Todavia, se os atributos do artefacto representado inicialmente na encomenda constituem, sob a forma de prescrições, uma finalidade ou um desejo para os autores da encomenda, não constituem uma finalidade ou um desejo para o SC, a menos que os assimile ele próprio a um estado desejado para o artefacto.

7 Esse estado depende dos seus conhecimentos, dos meios de conceção de que dispõe no momento em que é solicitado por uma encomenda, das suas afinidades ou do seu desinteresse por certos artefactos ou tecnologias. Depende igualmente de esquemas imaginários que assombram o SC, mas também os valores éticos e estéticos que defende com maior ou menor intransigência ou diplomacia, com mais ou menos emoção. Estes diferentes aspetos justificam uma abordagem pluridisciplinar. 
O SC é um objeto de conhecimento abstrato-concreto construído para descrever esses diferentes aspetos: um sujeito psicológico mas também histórico que concebe artefactos. Empiricamente o SC é sempre um objeto concreto e observável, um profissional confrontado com uma tarefa e identificado como praticante de uma profissão e isto em determinadas condições (assalariado de uma grande empresa, responsável de uma agência em situação liberal, experiente ou principiante, especializado ou não, etc.).

9 Enquanto profissional este sujeito é o herdeiro histórico de um progresso técnico, de uma formação e de uma experiência. Foi formado numa instituição da qual herdou tradições e crenças, aperfeiçoou-se a seguir praticando o seu ofício sem por isso neutralizar as contribuições da sua formação. É produtor de ações que arrastam transformações materiais da realidade (despesa e consumo de energia e de dinheiro, utilização de tecnologias, interação com outras pessoas, participação na produção de riqueza e de valores de uso, influência no modo de vida das pessoas que utilizam os artefactos que concebeu, etc.).

10 Enquanto construção teórica o SC é sempre um objeto abstrato. É um sistema complexo de conhecimentos e de ações. Sistema esse que é auto-organizado. Para alcançar os seus fins utiliza e coordena meios que lhe permitem realizar as tarefas de conceção adaptando-se a diferentes situações. Estes meios são automatismos, conceitos e redes de conceitos, esquemas, esquemas de raciocínio, crenças, métodos aprendidos nas escolas ou forjados pela experiência, algoritmos e heurísticas, sistemas de valores, estratégias, sistemas de sinais, habilidade técnicas, instrumentos cognitivos, imagens ou modelos mentais, representações simbólicas, fantasmas. Esta lista agrupa globalmente os conhecimentos tais como os definem diferentes abordagens cognitivas (Piaget, 1967; Le Ny, 1989; Rastier, 1991; Bachimont, 1992; Johnson-Laird, 1994; Hoc, 1996), mas também outras abordagens como as da semiologia e da psicanálise.

11 Por em evidência estes conhecimentos e a descrição do modo como o SC os utiliza requer que sejam considerados como «entidades ou atividades reais com o seu próprio nível de existência e de descrição» (Le Ny, 1989, p. 31). Uma representação verbal, uma imagem mental, o conceito de «belo», a realização de um desenho, o cálculo das cotas do volume da casa desenhada à mão, as utilizações do decalque, a simulação em computador das imagens visualizadas por um passeante virtual no interior de uma habitação que não existe senão no estado abstrato de plano geométrico, a crença segundo a qual «o número de ouro» é o melhor método de cálculo para obter relações de proporção harmoniosas entre as diferentes partes duma construção ou de um candeeiro, a planificação temporal de uma tarefa de conceção completamente condicionada por um projeto ergonómico, são outras tantas formas empíricas de utilização de conhecimentos.

12 A abordagem pluridisciplinar desta diversidade de conhecimentos e de domínios do conhecimento tal como a das suas formas de aplicação não relevam nem de um empreendimento polémico dirigido contra o purismo das disciplinas nem de uma procura de originalidade e ainda menos de um ecumenismo epistemológico que reduziria a sua complexidade a um sistema de lugares comuns. A pluridisciplinaridade é a primeira a beneficiar da fecundidade heurística específica de cada disciplina.

13 Todavia a abordagem pluridisciplinar é diferente, por necessidade, daquela que propõe cada disciplina isolada. Ela é mais adequada às realidades do trabalho humano (combinando, nas suas formas empíricas, dimensões históricas, sociais, tecnológicas, 
psicológicas, semiológicas, etc.). É suscetível de inspirar enriquecimentos críticos como também clarificações múltiplas no interior de cada disciplina. Pode ajudar a situar e a redefinir certas complementaridades metodológicas que as disciplinas estão em condições de oferecer à análise das condutas humanas² .

A abordagem pluridisciplinar permite definir a atividade do SC sob um ângulo simultaneamente cognitivo e semiológico. A atividade de um concetor depende de um complexo de interações que o ligam aos diferentes polos de uma situação de conceção: tecnologias, uma tarefa prescrita, outras pessoas, fontes de conhecimentos, a competência do próprio concetor.

Esta última interação (entre o SC e a sua própria competência) permite definir o SC como uma unidade de controlo relativamente autónoma, capaz de antecipar ou de modificar, em função das finalidades em que se fixou, as suas ações e decisões, tanto quanto a situação de conceção e a sua evolução. Para que essas interações sejam finalizadas pela realização de um modelo de artefacto o SC deve controlá-las e nomeadamente controlar os conhecimentos espontâneos que lhe fornece a sua própria competência.

16 As principais referências teóricas e metodológicas que orientaram os estudos de caso relatados nesta obra são facilmente referenciados: a epistemologia genética, a psicologia cognitiva, a linguística e a semiologia funcionais, a didática bem como os modelos propostos pela inteligência artificial para formalizar procedimentos de resolução de problemas e a didática.

17 São amplamente completadas por diferentes trabalhos de psicologia ergonómica (Leplat, 1993) e de ergonomia cognitiva (Visser e Hoc, 1990; Falzon, Bisseret et al., 1990; Bonnardel, 1992; Visser, 1995; Darses, 1994; Meniru, Rivard e Bédard, 2003) que permitiram clarificar e planificar a aplicação desses conhecimentos a terrenos empíricos de conceção.

Esta exploração de situações reais de conceção e esta abordagem disciplinar não conseguiriam alcançar aqueles poucos esclarecimentos completamente centrados (que estavam) na atividade cognitiva do sujeito-concetor, a não ser por terem sempre beneficiado da colaboração e das críticas de outros especialistas, no quadro coletivo da investigação pública: professores do (ensino) técnico e das artes aplicadas, de arquitetura, investigadores em psicologia ergonómica, peritos de revistas científicas, mas também atores concretos da conceção (técnicos, engenheiros, concetores profissionais, estudantes (em conceção).

19 Se esta apresentação da situação de observação e análise tende a aproximar a atividade do observador-analista da de um SC, como poderá dar-se conta o leitor atento desta obra, a comparação é todavia limitada. O valor de um objeto físico em três dimensões concebido por um especialista para satisfazer um uso social bem definido (automóvel, casa, imagem numérica, radio comando de grua, computador, par de meias, etc.) pode constatar-se imediatamente e de maneira precisa, desde a colocação em serviço. Não é o caso de um modelo da atividade de conceção empregue por um investigador nos seus trabalhos.

Este livro divide-se em quatro partes.

21 A primeira ('Problemática, teoria e métodos') é composta por cinco capítulos. Um primeiro capítulo descreve o quadro empírico construído e explorado para as necessidades da análise: o SC colocado no centro de um complexo de interações. Os 
quadros teóricos que permitiram abordar a atividade cognitiva e individual de conceção numa perspetiva pluridisciplinar são definidos num segundo capítulo. Um terceiro capítulo é consagrado às representações produzidas e manipuladas pelo SC. Os dois outros capítulos descrevem em detalhe os métodos de análise de conteúdo aplicados sucessivamente às verbalizações e às sucessões de desenhos produzidas pelo $\mathrm{SC}$. Estes métodos têm por finalidade extrair das representações produzidas pelo SC e das suas dinâmicas de produção, os traços essenciais da sua atividade.

A segunda parte ('Desdobramento cognitivo, planificação, organização coletiva') é centrada nos principais meios de controlo e de regulação da atividade de conceção desenvolvida pelo SC. Quatro capítulos restituem as análises detalhadas da atividade de arquitetos e de designers industriais, sob a forma de estudos de caso. A tónica é colocada nas semelhanças e diferenças entre arquitetura e design industrial. Todavia a questão do controlo exercido pelo SC sobre a sua própria atividade está presente nos dois domínios de conceção como também as diferentes utilizações do desenho que permitem a um arquiteto e a um designer construir um modelo definitivo de artefacto. $O$ desenho aparece como o principal meio de o SC controlar a incerteza e a precisão das informações que definem o artefacto que concebe. Por fim um quarto capítulo mostra como a organização coletiva do trabalho de conceção assegura ao SC uma parte essencial dos referentes de controlo e de regulação da sua atividade através da assistência que lhe prestam os colaboradores, eles mesmo produtores de uma atividade de conceção e dominando diferentes sistemas informáticos de representação e de comunicação (sistemas CAO).

A terceira parte ('O SC herdeiro do progresso técnico e das suas consequências organizacionais') mostra em três capítulos como os progressos fulgurantes das tecnologias de tratamento e de comunicação da informação e, nomeadamente, os conseguidos pela conceção assistida por computador (CAO) influenciaram a atividade do SC tal como a organização coletiva na qual se inscreve. O progresso técnico reforçou manifestamente a densidade e o dinamismo da rede sociotécnica da qual o SC extrai uma parte essencial dos meios de regulação da sua atividade. Todavia duas constatações resultam destas observações e análises. Quaisquer que sejam estas novas condições de conceção o desenho manual mantém-se um utensílio e uma fase indispensável da conceção. Estas análises mostram que a eficácia da rede de assistência que permite ao SC realizar os seus modelos depende da experiência de especialistas que conheçam perfeitamente as condições de realização material do artefacto a conceber.

Uma quarta e última parte ('Os concetores em situação didática') reúne, em dois capítulos, análises da atividade do SC em período de formação inicial. A tónica é colocada na importância da herança histórica que os professores transmitem na sua contribuição para a construção de uma competência de conceção. As estratégias didáticas que consistem, para os professores, em privilegiar a atividade cognitiva do estudante à custa de uma reprodução sistemática das práticas profissionais, abrem perspetivas concretas ao papel que pode desempenhar a psicologia, no domínio da aprendizagem dos conhecimentos de conceção e, mais generalizadamente no da didática. 


\section{NOTAS}

1. Em arquitetura este modelo poderá evoluir logo que a construção que representa esteja em curso num estaleiro: por exemplo, na sequência da utilização de um material do qual o arquiteto ignorava a existência e do qual não tomou conhecimento senão depois de terminados os seus planos, em plena fase de construção do edifício.

2. Por exemplo a análise de conteúdo de enunciados verbais ou de desenhos deve ter em conta diferenças entre semântica inferencial e semântica referencial, entre o 'significado' dos linguistas e o 'conceito' definido pelos psicólogos (Lyons, 1978; Rastier, 1991), ou ainda entre os 'conhecimentos' definidos pela inteligência artificial e aqueles que o são pela psicologia (Bachimont, 1992). 